\title{
Política Cognitiva Produtivista: Desenvolvimento e Hierarquia de Habilidades na Pós-Graduação
}

\author{
Vanessa Soares Maurente ${ }^{1}$ \\ Carlos Baum ${ }^{1-I n}$ memoriam \\ ${ }^{1}$ Universidade Federal do Rio Grande do Sul, RS, Brasil. $\quad{ }^{1}$ Universidade Federal do Rio Grande do Sul, RS, Brasil. \\ Renata Kroeff ${ }^{1}$ \\ ${ }^{1}$ Universidade Federal do Rio Grande do Sul, RS, Brasil.
}

\begin{abstract}
Resumo: Na perspectiva da teoria enativa da cognição, uma habilidade pode ser compreendida como uma relação flexível de um organismo com aspectos de seu ambiente de modo que ele possa agir de forma bem sucedida. Por sua vez, o conceito de políticas cognitivas nos ajuda a compreender como habilidades são promovidas e distribuídas em diversos contextos. Consideramos que os modelos de avaliação da produtividade acadêmica promovem arranjos que tendem a enfatizar um plano no qual os resultados ganham maior relevância na escala produtiva do que o desmembramento das "soluções" já existentes em problemas. Sendo assim, o objetivo deste artigo é entender o modo como as formas de avaliação dos programas de pós-graduação no Brasil podem modular noções de habilidades acadêmicas - hoje baseadas, principalmente, em publicações, invisibilizando outros processos que envolvem a produção de conhecimento e a experiência do pesquisador. Para tanto, realizamos uma pesquisa-intervenção junto a estudantes de cinco programas de pós-graduação de universidades públicas e privadas, na qual foram utilizados os procedimentos de entrevistas semiestruturadas e oficinas de fotografia. Por meio das entrevistas com as estudantes de engenharia e o estudante da veterinária, destacadas neste artigo, percebemos como o funcionamento acadêmico pressupõe a habilidade de pesquisar como um atributo que pertence ao indivíduo e reconhece/visibiliza em maior quantidade as habilidades consagradas nas sessões de procedimentos em métodos de artigos científicos, tratando como expert aquele que reproduz com precisão modos de fazer previamente especificados.
\end{abstract}

Palavras-chave: Cognição, Produtivismo Acadêmico, Habilidades, Enação.

\section{Productive Cognitive Policy: Development and Hierarchy of Skills in Graduate Courses}

\begin{abstract}
From the perspective of the enative theory of cognition, an ability can be understood as a flexible relationship of an organism with aspects of its environment so that it can act in a successful way. In turn, the concept of cognitive policies allows to understand how skills are promoted and distributed in diverse contexts. We consider that the models of evaluation of academic productivity promote more relevant results than transformation of existing "solutions" into problems. The objective of this article is to understand how the forms of evaluation of graduate programs in Brazil modulate a notion of academic abilities based, mainly, in publications, decreasing the importance of other processes involving the production of knowledge and the experience of the researcher. For such, we conducted an intervention research with students from five graduate programs of public and private universities utilizing semi-structured interviews and photography workshops. The results show how academic
\end{abstract}


functioning assumes the ability to research as an attribute that belongs to the individual. They emphasise the abilities acknowledged only in scientific methods, considering as experts students able to reproduce standard practices.

Keywords: Cognition, Academic Productivism, Skills, Enaction.

\title{
Política Cognitiva Productivista: Desarrollo y Jerarquía de Habilidades en el Posgrado
}

\begin{abstract}
Resumen: En la perspectiva de la teoría enactiva de la cognición, una habilidad se entiende como una relación flexible de un organismo con aspectos de su ambiente para que pueda actuar de forma exitosa. Por su parte, el concepto de políticas cognitivas nos ayuda a comprender cómo las habilidades son promovidas y distribuidas en diversos contextos. Consideramos que los modelos de evaluación de la productividad académica promueven arreglos que tienden a enfatizar un plan en el cual los resultados ganan mayor relevancia en la escala productiva que el desmembramiento de las "soluciones" ya existentes en problemas. Ante esto, el objetivo de este artículo fue entender cómo las formas de evaluación de los programas de posgrado en Brasil pueden modular nociones de habilidades académicas, basadas actualmente en publicaciones, invisibilizando otros procesos que involucran la producción de conocimiento y la experiencia del investigador. Para ello, realizamos una investigación-intervención junto a estudiantes de cinco programas de posgrado de universidades públicas y privadas, en la cual se utilizaron los procedimientos de entrevistas semiestructuradas y talleres de fotografía. De las entrevistas con las estudiantes de ingeniería y el estudiante de veterinaria, destacadas en este artículo, percibimos cómo el funcionamiento académico presupone la habilidad de investigar como un atributo que pertenece al individuo y reconoce/posibilita en mayor cantidad las habilidades más consagradas en las sesiones de procedimientos en métodos de artículos científicos tratando como experto aquel que reproduce con precisión modos de hacer previamente especificados.
\end{abstract}

Palabras clave: Cognición, Productivismo Académico, Habilidades, Enación.

\section{Introdução}

Institucionalmente atribuímos o status de cientificidade a um conhecimento a partir do momento em que ele é avaliado pelos pares e publicado formalmente. Classicamente, para poder apropriar-se do adjetivo "científico", conforme os princípios instituídos que regem o que é e o que não é ciência (Bachelard, 1971), um determinado conhecimento deve atingir patamares de controle e/ou credibilidade alcançados por meio de métodos específicos. Porém, a publicação de um artigo científico, por exemplo, não contém nem encerra - por mais precisas que sejam as descrições metodológicas - a plenitude dos saberes e práticas necessários para o desenvolvimento de uma pesquisa. Ou seja, em última instância, o conhecimento científico registrado e validado depende de um conjunto de práticas e habilidades apenas marginalmente atreladas ao contexto científico (Latour, 2001), mas que constituem os pesquisadores em suas experiências de pesquisar e são imprescindíveis para a produção de conhecimento. Este saber, relacionado às habilidades e experiências de um pesquisador empregado no desenvolvimento de suas atividades científicas, é difícil de ser comunicado formalmente, adquirindo pouca visibilidade em função da ênfase na divulgação científica tradicionalmente ligada à cultura acadêmica do produtivismo.

$\mathrm{O}$ produtivismo acadêmico tem origem nos Estados Unidos, na década de cinquenta, tendo sua máxima na expressão "publish or perish", que simbolizava a forte presença das exigências de mercado na academia, o controle dos órgãos financiadores e a entrada da perspectiva capitalista de trabalho no 
campo acadêmico, no qual o alto nível de produção passa a ser imprescindível para a manutenção da carreira (Tourinho \& Bastos, 2011). No Brasil, este fenômeno surge nos anos setenta, sendo institucionalizado como uma política de avaliação nos anos noventa, com a construção de metodologias quantitativas pela Coordenação de Aperfeiçoamento de Pessoal de Nível Superior (CAPES).

A amplitude do efeito das transformações nas políticas de avaliação brasileiras pode ser analisada por meio de dados que afirmam que, entre 1981 e 2006, a produção científica no mundo duplicou, enquanto a brasileira se multiplicou por nove (Tourinho \& Bastos, 2011). Alguns autores o consideram como o resultado de uma "ciência-salame", ou seja, da divisão do que seria um único artigo no maior número possível de produções a serem publicadas em revistas diferentes (Castiel \& SanzValero, 2007). Ao longo dos anos, as formas de avaliação foram se aprimorando, incorporando novos critérios para as avaliações dos programas de pós-graduação, como proposta do curso, quantidade de citações das publicações e inserção social - este último amplamente debatido no XIV Simpósio da Associação Nacional de Pesquisa e Pós-Graduação em Psicologia, em 2001, por não ter uma definição consensual entre coordenadores e orientadores (Sato, Teodoro, Linhares, Maraschin, \& Carneiro, 2012).

Cabe salientar, entretanto, que não são somente as formas institucionalizadas de avaliação que produzem efeitos sobre os modos de pesquisar. O imperativo da competitividade em seu estado ubíquo entra nas universidades por inúmeras vias, resultando em visibilidades que enfatizam trajetórias individuais. Como efeito de tais processos de avaliação, tem-se observado o crescimento da competitividade entre pares, valorização da quantidade e da velocidade em detrimento da qualidade, escolha de temas menos complexos e pressão institucional (Maraschin \& Sato, 2013).

Outra consequência importante de uma política direcionada à produtividade nos cursos de pós-graduação pode ser o empobrecimento da formação didático-pedagógica de professores atuantes na graduação (Vosgerau, Orlando, \& Meyer, 2017). A pressão para alcançar altos níveis de produção também pode produzir sofrimento físico e psíquico, desencadeando processos de adoecimento (Estácio, Andrade, Kern, \& Cunha, 2019). Este aspecto, por sua vez, pode estar relacionado com o que Andrade, Canssundé e Barbosa (2019) descrevem como uma "gaiola de cristal" que priva o pesquisador de liberdade quando o coloca em busca de resultados e produtividade, desencorajando-o a investir em processos criativos.

Neste artigo, interpelamos o modo como o produtivismo ligado aos programas de pós-graduação no Brasil modulam uma noção de habilidades acadêmicas baseada, principalmente, em publicações, invisibilizando e/ou desvalorizando outros processos que envolvem a produção de conhecimento e a experiência do pesquisador. A questão é abordada a partir do conceito de políticas cognitivas, apresentado por Kastrup (2006). Com esse conceito a autora propõe um deslocamento do interesse no funcionamento e na estrutura da cognição para as práticas concretas que a configuram. Sua discussão sugere duas políticas distintas operando no campo da educação: uma recognitiva, centrada nos resultados e na solução de problemas, buscando assegurar um domínio do mundo; e outra inventiva, pautada pela promoção da continuidade da cognição no campo da multiplicidade e do agenciamento. Essa segunda política busca uma constante abertura da cognição para o novo e um movimento incessante de diferenciação, mantendo qualquer regra de funcionamento como temporária e passível de reinvenção. Ao longo dos anos um grande número de autores (Kastrup, 2006; Rocha \& Pinheiro, 2011) recorreu à expressão política cognitiva como alternativa à expressão modelo cognitivo - mais especificamente os modelos cognitivistas, que descrevem o funcionamento da mente em termos de representações mentais e procedimentos computacionais que atuam sobre tais representações, posição que Kastrup problematiza recorrentemente. Esse uso confunde uma postura em relação às pesquisas em cognição - o foco nas práticas com uma política específica defendida pela autora ${ }^{1}$.

Quando orientamos nossa análise para o modo como as práticas científicas no Brasil configuram a cognição por meio da valorização de habilidades específicas, podemos pensar que uma política cognitiva produtivista organiza essa hierarquização. Nossas análises conectam o conceito de política cognitiva

${ }^{1}$ Sobre a relação entre políticas cognitivas e modelos, ver Gavillon, Baum e Maraschin (2017). 
com o de habilidades, desenvolvido extensamente na teoria da enação ${ }^{2}$, permitindo, no sentido oposto, empregar conceitos sobre cognição incorporada na discussão sobre práticas de pesquisa.

Assim, iniciaremos pela apresentação da noção de habilidades na perspectiva da teoria da enação, seguida da discussão sobre políticas cognitivas no contexto acadêmico produtivista. Após a especificação da metodologia utilizada, traremos elementos das entrevistas realizadas junto aos estudantes de pós-graduação, articulando análises a fim de pensar como as políticas cognitivas no contexto produtivista podem estar visibilizando e invisibilizando aspectos da formação de pesquisadores e de suas habilidades. Para finalizar, argumentamos em relação à emergência de uma política cognitiva produtivista no contexto brasileiro sustentada a partir das atuais políticas de pesquisa.

\section{Habilidade na Teoria da Enação}

Chamamos de habilidade um tipo de conhecimento que possuímos mas que é de difícil articulação verbal, comumente associado a termos como conhecimento tácito, saber prático/operativo, competência e expertise, usados para descrever um conhecimento ou capacidade para desempenhar uma tarefa específica. Estes conhecimentos são caracterizados como enraizados na experiência direta, de difícil verbalização - não sendo completamente verbalizáveis -, muito específicos e contextualizados.

O conceito de habilidade ${ }^{3}$ aparece no centro da proposta enativa uma vez que é utilizado para contrapor a noção - central no cognitivismo - de que podemos compreender nossas capacidades cognitivas em termos de representações mentais de um mundo pré-existente que subjazem às nossas ações. Varela et al. (2001), por outro lado, propõem que o que permite um engajamento inteligente com o mundo não depende da implementação de um conhecimento explícito e proposicional, mas sim de uma acumulação de experiência. Cria-se, com isso, uma dicotomia a respeito das bases do funcionamento cognitivo. De um lado como conhecimento proposicional, baseado no processamento de representações, consistindo essencialmente de uma crença justificada que pode ser articulada na forma de proposições e regras de manipulação a partir de um conjunto delimitado de estados possíveis (seja do sujeito, seja do mundo). Em contrapartida, na teoria enativa, habilidade se refere a um conhecimento não representacional: é o que permite alcançar determinados resultados de forma confiável ou se envolver em atividades específicas com competência. Assim, eu sei como amarrar meus sapatos, andar de bicicleta, jogar tênis, mas essas capacidades não dependem de um conjunto de regras proposicionais que antecedem a ação. $\mathrm{O}$ resultado disso é que não podemos dizer como conseguimos tais feitos articulando um conjunto de regras tácitas ou seguindo máximas.

Os estudos cognitivos baseados no processamento de informação que tratam do desenvolvimento de habilidades se baseiam na existência de um controlador central, seja ele um self ou um modelo mental responsável pela organização e regulação da ação. A partir dessa posição, o desenvolvimento de habilidades se dá pelo estabelecimento de mecanismos, esquemas ou programas - que representam ações - que foram, por sua vez, adquiridos em experiências de aprendizado e cumprimento de tarefas e armazenados internamente. Essa posição coloca o desenvolvimento de habilidades como a aquisição de algo durante o aprendizado, como um aumento no número de estados mentais possíveis, um incremento na quantidade de conhecimento na memória ou como representações mais sofisticadas de movimentos como resultado da prática.

\footnotetext{
${ }^{2}$ A teoria enativa proposta por Varela, Thompson e Rosch (2001) assume que toda cognição é uma forma de ação incorporada. Estruturas e processos cognitivos emergem de padrões sensório-motores recorrentes, constituindo um acoplamento sensório-motor ao ambiente que, por sua vez, modula, mas não determina, a formação de padrões dinâmicos de atividade. Esses padrões, retroativamente, dão forma ao acoplamento sujeito-mundo. Com isso, o mundo de um sujeito cognitivo não é um domínio exterior e predeterminado que deve ser adequadamente representado no cérebro, mas um domínio relacional, que precisa ser atuado, trazido à existência por meio da ação do sujeito cognitivo em seu modo de acoplamento com o mundo.

${ }^{3}$ Desse ponto em diante no texto nos utilizamos da palavra habilidade para condensar dois termos do inglês: skill e know-how. Estes são quase sempre utilizados como sinônimos na literatura sobre enação. Know-how foi traduzido anteriormente como competência, como no caso de "Sobre a competência ética" (Varela, 1996) [Ethical know-how, no original]; entretanto, o termo competência nos últimos 20 anos foi profundamente associado às reestruturações curriculares influenciadas pelas transformações no capitalismo e novos modelos de gestão empresarial, conduzindo à ideia de uma redução na capacidade do trabalhador de refletir sobre sua condição (Brito, 2008; Deluiz, 2001; Lima, 2004).
} 
Na perspectiva enativa podemos propor o desenvolvimento de habilidades em um domínio específico como o estabelecimento de uma relação recíproca e funcional entre um organismo/sujeito e seu meio caracterizada pelo aumento gradual da sensibilidade de variáveis perceptuais relevantes e, concomitantemente, pelo ajuste e refinamento de ações relacionadas. A dinâmica do ambiente e do organismo estabelecem uma reciprocidade, constituindo um processo emergente comum a ambos. Com isso, podemos definir cognição como a habilidade de cada indivíduo perceber as modulações do ambiente de acordo com sua capacidade para a ação. Cabe destacar que o desenvolvimento dessa dinâmica mútua não está restrito a características físicas do mundo ou a capacidades cognitivas consideradas básicas (como caminhar, praticar um esporte ou tocar um instrumento), mas à experiência do sujeito em redes sociotécnicas.

Na perspectiva da enação, uma habilidade pode ser compreendida como uma relação flexível de um organismo com aspectos do ambiente de modo que esse possa agir de forma bem sucedida e regular. Apesar de ser uma definição ampla, que se aplica a quase qualquer comportamento adaptativo ${ }^{4}$ de um organismo independentemente de sua simplicidade ou complexidade, essa definição de habilidade nos permite traçar uma continuidade entre capacidades sensoriais básicas e ações de "ordem superior", como jogar xadrez, escrever um artigo científico ou operar um computador. Para a teoria enativa, a lógica e a abordagem para entender esses diferentes domínios de experiências são fundamentalmente semelhantes (McGann, De Jaegher, \& Di Paolo, 2013). Nessa perspectiva, uma habilidade bem sucedida resulta na emergência de um comportamento que é acomodável a uma gama de contextos de performance. O comportamento flexível é uma característica importante da habilidade porque restrições do ambiente, das exigências da tarefa ou da intenção do indivíduo alteram-se cada vez que a ação é executada. O comportamento hábil e adaptável, ao invés de ser imposto por alguma estrutura pré-existente (como representação ou plano de ação), emerge da confluência de restrições que delimitam as condições de uma tarefa em particular.

Quando se diz que um garoto adolescente é uma revelação no futebol, raramente se considera que ser um bom jogador ultrapassa o bom desempenho em campo. A habilidade de jogar futebol é avaliada pela dinâmica estabelecida com a bola e com os demais jogadores. Entretanto, ao ser contratado por um time no exterior, jogadores jovens terão que aprender a falar outro idioma, a suportar diferenças climáticas, a lidar com a solidão, a regular sua alimentação, a perceber-se como estrangeiro e, ainda, a manter o mesmo desempenho no futebol. Obviamente, isto é possível, mas, além das habilidades esportivas, nenhum dos outros fatores acima, a priori, é considerado importante para ser um bom jogador. Isto tem a ver com o modo como estabelecemos o domínio de ação de jogar futebol: uma distinção feita pelo observador que seleciona algumas ações e provoca a invisibilização de outras.

A noção de habilidade como um processo fechado, localizado no sujeito e mensurável ainda é hegemônica, o que produz muitos efeitos em nossos modos de agir. Algumas instituições se utilizam de estratégias de arranjo das atividades humanas seguindo uma definição representacionista e universal de expertises, que se tornam quase um ideal a ser alcançado. No caso da (instituição) ciência, por exemplo, o que compreendemos como possibilidade de medida da habilidade de um pesquisador, geralmente, se refere muito mais à capacidade de publicar resultados em artigos do que aos processos que possibilitam sua escrita e produção. A seguir, discutimos como o conceito de políticas cognitivas nos ajuda a refletir sobre a institucionalização e avaliação da distribuição de habilidades.

\section{Políticas Cognitivas e Produção de Conhecimento Científico}

Partindo da teoria da enação para pensar a relação entre cognição e instituições, Kastrup (2006) desenvolve a noção de políticas cognitivas, que nos permite situar o problema das habilidades acadêmicas no contexto produtivista. A autora aborda a processualidade em jogo no operar cognitivo e propõe que desloquemos o foco da atenção em nossas pesquisas dos limites de operação da cognição para as práticas que as modulam. Uma política cognitiva varia dependendo do arranjo e das relações entre seus atores. Em cada um desses arranjos são constituídas

\footnotetext{
${ }^{4}$ O termo "adaptativo" na teoria da enação não faz referência a noções como acomodação ou conformação, mas relaciona-se com todas as transformações estruturais (em especial os comportamentos) que ganham estabilidade em congruência com uma normatividade interna, como a bactéria que nada em direção a uma maior concentração de alimento ou um bebê que chora quando tem fome.
} 
e distribuídas modalidades de relações, assim como são negociadas as possibilidades de ação de cada ator. O que se obtém nesses arranjos são agenciamentos heterogêneos compostos por sujeitos, técnicas, objetos e instituições. Pesquisar a cognição nessa abordagem implica acompanhar, por meio de suas práticas, o modo como uma operatividade se constrói em cada política (Maraschin, Baum, Teles, \& Roos, 2016).

Inspirados por Kastrup adotamos o conceito de política cognitiva como uma forma de se referir e comparar conjuntos específicos de sujeitos, técnicas, instrumentos e instituições que produzem a mente, ressaltando como nossas práticas moldam e configuram nossa cognição de várias maneiras. Neste artigo, propomos que o conceito de políticas cognitivas nos ajuda a compreender como habilidades são promovidas e distribuídas no contexto da formação em pesquisa. Destacamos como alunos de pós-graduação necessitam construir uma rede de competências corpóreas de difícil verbalização - como lidar com pessoas, encontrar estratégias frente a recursos para pesquisa cada vez mais escassos e suportar a pressão sem adoecer - que, por sua vez, sustentam e tornam possível a execução de capacidades consideradas hierarquicamente superiores, como a escrita de artigos divulgando os resultados. O entendimento implícito nesses casos situa a habilidade de pesquisar como um atributo que pertence ao indivíduo, e reconhece/visibiliza em maior quantidade as habilidades mais consagradas nas sessões de procedimentos em métodos de artigos científicos, tratando como expert aquele que reproduz com precisão modos de fazer previamente especificados. Em contrapartida, ressaltamos que a aprendizagem de habilidades envolvidas no pesquisar na pós-graduação extrapola, em diversos sentidos, aquilo que "aparece" nas produções reconhecidas pelas avaliações. Buscamos, com isso, propor que as experiências promovidas pela pós-graduação produzem modos de especificação dos problemas a serem resolvidos e, portanto, as habilidades necessárias para resolvê-los são um feito emergente de um processo de codeterminação sujeito-mundo.

\section{Método}

Apresentaremos alguns recortes de uma pesquisa de campo, realizada por meio do projeto intitulado Fotografia e pesquisa-intervenção: construção de estratégias para a produção inventiva na pós-graduação, aprovado por parecer consubstanciado do Comitê de Ética em Pesquisa com o número 1.971.700. Tal projeto tem como tema geral o estudo das relações entre produção de subjetividade, políticas cognitivas e as atuais políticas de avaliação da pós-graduação no Brasil. Partindo de uma escolha político-metodológica baseada na pesquisa-intervenção $0^{5}$, realizamos entrevistas semiestruturadas e oficinas de fotografia junto a nove estudantes de cinco programas de pós-graduação de universidades públicas e privadas de Porto Alegre ${ }^{6}$. As áreas contempladas foram: psicologia, educação, bioquímica, veterinária e engenharia.

Nas entrevistas semiestruturadas foram colocadas algumas questões sobre o modo como os estudantes percebiam as formas de avaliação e reconhecimento de seu trabalho. Tais questões foram: como você percebe seu ambiente de pesquisa e aprendizagem? Você já percebeu situações de competitividade entre pares na universidade? Por que você acredita que estas situações ocorreram? Qual sua temática de pesquisa? Você acredita que seu trabalho ultrapassa aquilo que dele pode ser avaliado nas atuais políticas acadêmicas? Você poderia descrever algumas situações de pesquisa que considera invisíveis a quem

\footnotetext{
${ }^{5}$ A pesquisa-intervenção parte do movimento institucionalista, que teve seu início na França, na década de sessenta, e na América Latina na década seguinte. Tal movimento tinha como característica a desnaturalização das instituições, consideradas como práticas socialmente produzidas que articulam e naturalizam formas de viver. Como nem sempre estas práticas estão a serviço do desejo, é necessário que se assuma uma posição de questionamento em relação a elas. No campo da pesquisa, os efeitos deste movimento apontam para o rompimento com as noções de verdade e neutralidade, considerando-se que a ciência é, também, uma instituição a ser colocada em análise. Além disso, surgem práticas metodológicas, como a análise de implicações (Lourau, 2004) - que desloca o foco para o próprio pesquisador e seus atravessamentos institucionais - e a pesquisa-intervenção (Rocha \& Aguiar, 2010) - que tem como característica a construção de dispositivos mobilizadores junto aos campos de pesquisa, a fim de intensificar e visibilizar as práticas instituídas para, no coletivo, poder problematizá-las e transformá-las. Trata-se de um estudo em processo, no qual pesquisadores, sujeitos, instituições e conhecimento se produzem em coengendramentos. No projeto mencionado, a metodologia da pesquisa-intervenção se deu a partir da realização das oficinas de fotografia e construção de análises junto aos sujeitos de pesquisa. Considerando que o objetivo deste artigo é discutir a relação entre a noção de habilidades no contexto da teoria da enação e uma política cognitiva produtivistas na academia, iremos nos ater somente à primeira parte da intervenção realizada no projeto, ou seja, as entrevistas.

${ }^{6}$ As universidades nas quais o estudo foi realizado não serão mencionadas a fim de garantir o sigilo. Com o mesmo objetivo, iremos utilizar nomes fictícios para nos referirmos aos estudantes.
} 
acompanha artigos, teses e dissertações? Todas as entrevistas foram gravadas e transcritas.

Após as entrevistas, convidamos os participantes a fotografarem, durante uma semana, aquilo que consideravam fazer parte de suas pesquisas, mas não ser reconhecido pelas formas de avaliação acadêmicas atuais. A produção fotográfica foi feita por meio dos smartphones dos estudantes, na universidade, em suas casas, nos campos de pesquisa e em trajetos pela cidade. Foram produzidas em torno de 10 a 12 fotografias por estudante.

Após a produção fotográfica, conversamos novamente com os pós-graduandos. As análises foram realizadas junto aos estudantes, conforme sustentam os pressupostos da pesquisa-intervenção, a partir das entrevistas e das imagens produzidas. Indo em uma direção distinta da racionalidade das pesquisas científicas tradicionais, as análises em pesquisa-intervenção buscam, ao invés de restringir, proliferar sentidos, abrindo novos campos de questionamento ao que está dado como solução (Barros \& Barros, 2013). Neste sentido, as análises que seguem não buscam generalizar as produções desta pesquisa específica para explicar definitivamente relações entre habilidades acadêmicas e produtividade, mas tomá-las como casos particulares, que, no entanto, abrem caminho para novas problematizações.

Barros e Barros (2013) também situam que, em pesquisa-intervenção, sujeitos se tornam também pesquisadores nas discussões alavancadas nos contextos de estudo. Ao olharmos as imagens junto com os pós-graduandos, produzimos reflexões de um modo coletivo e horizontal, sem a pretensão de tomá-las como generalizações, mas sim como pontos de inflexão para disparar questionamentos. Neste artigo, a fim de nos aprofundarmos na discussão sobre os habilidades e políticas cognitivas no cenário acadêmico brasileiro, iremos nos debruçar somente sobre as entrevistas realizadas com duas estudantes do doutorado em engenharia e um estudante de mestrado em veterinária, assim como sobre as análises realizadas junto a estes mesmos estudantes ao olhar suas fotos e, posteriormente, junto ao grupo de pesquisa.

\section{Resultados e Discussão}

Como anteriormente mencionado, os resultados desta pesquisa não permitem generalizações, mas o aprofundamento das discussões sobre como as avaliações dos programas de pós-graduação no Brasil podem modular noções de habilidades acadêmicas baseadas, principalmente, em publicações, invisibilizando outros processos que envolvem a experiência do pesquisador. No programa de engenharia, as duas doutorandas que aceitaram participar do projeto afirmaram nas entrevistas que realizam testes em modelos de processamento de cálculos em simulações computacionais. O objetivo das suas pesquisas é que estes modelos, que são mais simples (e rápidos) em relação a um modelo completo, entreguem resultados o mais próximo possível dos modelos já existentes. Assim, segundo elas, as pesquisas são voltadas para testar modelos e otimizar a velocidade dos processos.

A cada sete dias, Clara e Luiza afirmaram se reunir com o orientador, individualmente, a fim de apresentarem os resultados alcançados na semana, cuja margem de erro deve ser menor que 5\% para ser considerado válido. Salientaram que tais resultados são alcançados na menor parte das tentativas. Entretanto, Clara e Luiza dizem se sentir envergonhadas quando não os alcançam. Questionamos sobre a possibilidade de que resultados superiores à margem de $5 \%$ ocorram porque o modelo que foi testado não era tão preciso quanto os anteriores, e elas concordaram, mas geralmente tendem a pensar que, se o resultado foi "ruim", foi porque fizeram algo errado. Percebe-se que, neste caso, as políticas acadêmicas em questão enfatizam a velocidade da produção de resultados satisfatórios, em detrimento da problematização dos processos. A organização do tempo em torno dos percentuais de erro alcançados durante a semana indica um controle dos modos de fazer das estudantes, a fim de garantir que estejam produzindo bons resultados. No programa de pós-graduação da engenharia, a expertise - ou seja, a execução bem sucedida de uma habilidade - parece ser a capacidade do sujeito de encontrar modelos com uma margem de erro baixa, em um laboratório onde o objetivo da pesquisa é a velocidade.

Por outro lado, Clara e Luiza afirmaram que, quando alcançam os resultados, são convidadas a confirmá-los com um dos outros doutorandos homens - do grupo, em função de que estes seriam "mais experientes". Cabral (2005) salienta que as mulheres estiveram historicamente afastadas da produção científica e tecnológica, especialmente na área da engenharia. E que, apesar de não haver mais restrições explícitas para a participação feminina, inúmeras barreiras invisíveis ainda são mantidas, como 
a hierarquização dos sexos e a segregação. Em nossa pesquisa, Clara é a primeira doutoranda mulher de seu orientador, credenciado há quase vinte anos na pós-graduação. Outro professor, que teve duas orientandas que engravidaram durante os anos de pós-graduação, afirmou que nunca mais selecionaria uma mulher, ainda que uma das suas alunas não tenha desfrutado da licença maternidade e tenha finalizado o doutorado em três anos e meio. Olinto (2011) apresenta, por meio de dados obtidos pelo Conselho Nacional de Desenvolvimento Científico e Tecnológico (CNPq), que a hierarquização de gênero na ciência é um processo que envolve diversos tipos de privilégios aos homens, como promoções, obtenção de bolsas de produtividade e ocupação de cargos de chefia ou liderança.

A condição desprivilegiada da mulher na instituição em questão pode apontar para a desconfiança sobre um corpo que, em possível situação de maternidade, tenha que parar de produzir. Assim, quando falamos em políticas cognitivas, referimo-nos também a práticas tácitas que compreendem os aspectos da vida dos estudantes como possíveis entraves às publicações e perdem o fio da meada no que tange à formação e à problematização daquilo que já se conhece. Poderíamos pensar que, quando o que se prioriza é a busca por resultados em maior velocidade, o que "escapa" a este objetivo não é bem-vindo. Essa configuração pode conformar uma política que conecta a agência ao gênero, questionando e revisando as ações do corpo feminino, expondo erros com mais frequência e construindo um ambiente de desconfiança para mulheres que não é vivido por aqueles que possuem um corpo masculino.

A teoria da enação considera como expertise o processo muito mais amplo de construção de habilidades, caracterizado pelo aumento gradual da sensibilidade a variáveis perceptuais relevantes e, concomitantemente, o ajuste e refinamento de ações relacionadas. A dinâmica do ambiente e do organismo estabelecem uma reciprocidade, constituindo um processo emergente comum a ambos. As políticas cognitivas em jogo no espaço acadêmico cercam os modos de pesquisar com regras, regulamentos e práticas, legitimando certas habilidades e tendo como efeito a formação de expertises específicas. Entretanto, justamente para que tal expertise possa ser acionada, é necessária uma série de outras habilidades, não legitimadas e, mais do que isso, invisibilizadas.
Se, por um lado, uma política cognitiva produtivista na academia engendra formas da cognição que operam em prol de resultados (Maraschin \& Sato, 2013), por outro, no caso de Clara e Luiza, é necessário mais do que a habilidade com os modelos computacionais para "sobreviver" e produzir ações efetivas neste meio - como, no caso específico citado nesta pesquisa, finalizar um doutorado seis meses antes do prazo requerido. Clara e Luiza precisam também lidar com as questões de gênero socialmente construídas que atravessam o contexto institucional, sustentar-se em uma posição de pesquisadora no laboratório e lidar com a pressão por resultados exemplos de outras habilidades necessárias para garantir a efetividade de suas ações.

Algumas estratégias também se produzem coletivamente, como o seminário semanal, um espaço construído pelos alunos e para os alunos no qual estes apresentam suas pesquisas uns aos outros. Luiza afirma ter encontrado muitas respostas neste grupo, que trabalha numa perspectiva de ajuda mútua e dispensa o professor, com o objetivo de valorizar relações mais horizontais e não tão centradas na apresentação de resultados. Entretanto, tal espaço vem se esvaziando, em função de que o programa não contabiliza horas-aula para esta atividade e os pós-graduandos precisam "tocar" suas pesquisas, apresentar resultados e produzir artigos. Percebe-se que, neste programa, a estratégia para um certo tensionamento do modelo focado em resultados se desenha, mas rapidamente é capturada por um modo de operar que se faz "necessário" no contexto, validando habilidades que tenham como norte o produtivismo.

Outro fator que engendra este modo produtivista de operar no programa de pós-graduação específico no qual Clara e Luiza estudam são as formas de concessão de bolsas. Somente aquele aluno que alcança uma publicação em revista Al, após começar o mestrado ou o doutorado, é contemplado. Sendo assim, durante o início do curso, todos os alunos ficam sem auxílio financeiro para realizar sua pesquisa. Este período pode ser bastante extenso, levando mais de dois anos e inviabilizando a pós-graduação para os menos privilegiados. Conforme a disponibilidade de bolsas, alguns alunos a recebem após a publicação, como um prêmio e não como um direito. Clara e Luiza comentam que a expressão "premiação" é utilizada para a concessão. Além da precarização da situação de trabalho, tal medida leva à individualização dos 
processos científicos e à competição entre os colegas. "O que mais acontece é vermos alguém torcendo para o artigo do colega não ser aceito", diz Luiza.

No programa de pós-graduação em veterinária, encontramos outro exemplo que nos ajuda a pensar sobre como o produtivismo pode estar delimitando certos modos de operar na formação de habilidades. O mestrando que se interessou em participar do projeto realizava uma pesquisa sobre a fertilização e inseminação de gêmeos em diferentes raças de vacas. Quando realizamos a primeira entrevista ele estava prestes a fazer uma saída de campo para a zona rural, onde iria passar 40 dias realizando partos e cesarianas em 200 vacas previamente inseminadas. Nesta jornada, seria acompanhado de um doutorando do mesmo orientador e duas mestrandas. Guilherme nos contou que estava tendo muitas dificuldades no mestrado. Seu orientador se queixava de sua falta de habilidade com os instrumentos de laboratório. Além disso, não tinha conhecimento avançado em inglês e nem publicações anteriores ao mestrado. Por algumas destas razões, ele era o único pós-graduando sem bolsa do projeto, ou seja, não era valorizado pelas políticas institucionais.

Após quase dois meses, tivemos o segundo encontro com Guilherme, que havia voltado da zona rural. Em uma casa precária, com piso irregular e goteiras, os pesquisadores deveriam observar, através de um binóculo, 24 horas por dia, o movimento das vacas no campo. Caso alguma vaca apresentasse um comportamento diferente, poderia ser sinal de que estivesse entrando em trabalho de parto. Então, um ou mais pesquisadores deveriam ir até o local a cavalo. Caso o parto fosse tranquilo, eles deveriam pesar, verificar o sexo, coletar o pelo, marcar com ferro o número e preencher a ficha do animal. Além de fazer a avaliação dos bezerros, eles precisavam observar a relação desses com as vacas nas primeiras horas, pois, quando nascem gêmeos, é comum que a vaca rejeite um deles e não o permita mamar. Caso isso acontecesse, eles deveriam imobilizar a vaca no estábulo para que o filhote mamasse. Além disso, quando estava frio, precisavam enrolar os bezerros em cobertores. Caso o parto fosse difícil, deveriam realizar uma cesariana de urgência.

Já no primeiro dia, o doutorando, colega de Guilherme, entrou em conflito com um dos peões, que trabalhava há vinte anos na fazenda, ao ordená-lo, em tom ríspido, sobre o modo como deveria conduzir as vacas. Guilherme comentou que nunca se diz a um peão como deve ser sua relação com os animais, pois eles tem seu próprio modo de fazer que deve ser respeitado, mas o colega não o levou a sério. $\mathrm{O}$ peão fez uma queixa ao dono da fazenda, o que gerou um mal estar com os pesquisadores. O doutorando sentiu seu saber desafiado e buscou o apoio de duas mestrandas, que não compactuaram com ele. $\mathrm{O}$ clima foi se tornando tenso e, no quarto dia, as duas mestrandas e o doutorando, que nunca haviam estado em uma fazenda, retornaram à cidade. Foram enviadas duas bolsistas de graduação, de outra universidade, para ajudar Guilherme.

Quando experimentamos novos ambientes, de acordo com Kastrup (2001), os hábitos e habilidades anteriores nem sempre serão efetivos, pois a memória, a percepção e a sensibilidade parecem divergir, produzindo um estranhamento e um consequente distanciamento entre o saber anterior e a situação presente. Conforme a autora, somos forçados a pensar e produzir um novo domínio cognitivo. O campo, a fazenda, as vacas, o peão e os partos poderiam ter produzido nos estudantes, que nunca haviam estado em uma fazenda, possibilidades de estabelecer novas relações com seu conhecimento. Entretanto, quando colocado à prova, $\mathrm{o}$ saber-sobre dos pesquisadores com pouca experiência do contexto rural, no campo da veterinária, se mostrou inadequado, ineficaz e sem relação com a habilidade necessária à circunstância por eles vivida. O doutorando buscou acessar as habilidades acadêmicas já conhecidas para lidar com o mundo, permanecendo pouco sensível às variáveis perceptuais do novo contexto e fechando-se para a emergência de novos mundos.

As habilidades são sempre contextualizadas e inseridas em um domínio cognitivo, seja ele da engenharia ou da veterinária. Sua aprendizagem se dá por meio da prática em situações específicas - o laboratório - e sua atuação desenrola-se em cenários particulares de uma maneira sensível às especificidades desse contexto nesse caso específico, a fazenda. Com isso, o regulamento da precisão de uma ação não é localizável no interior de um sujeito, mas está distribuída entre a rede de atores de um meio sociotécnico. No caso da veterinária, algumas das habilidades do doutorando, que eram muito efetivas nauniversidade-como a escrita de artigos em inglês, a articulação teórica de conceitos e a análise estatística dos resultados -, eram reconhecidas por seus pares (orientador e outros pesquisadores). Contudo, quando as atividades da pesquisa extrapolaram o 
domínio de ação da escrita técnica e análise laboratorial, o saber sobre e o saber fazer associados a essas atividades não "fizeram sentido" no novo contexto de ação: ocampo dapesquisa desenvolvidonafazenda.A partirdo breakdown causado pela alteração do domínio de ação, o doutorando - colega de Guilherme - precisava efetuar novas coordenações para que um saber fazer localizado e efetivo fosse produzido. É possível que saberes anteriores participem desse processo estando envolvidos na modulação da atividade sensório-motora. Contudo, o saber agir em uma circunstância nunca pode ser reduzido a um saber sobre tal contexto, ou seja, mesmo que o doutorando tenha um conhecimento extenso a respeito de como é o cotidiano em uma fazenda, tal saber sobre não consegue ser transposto diretamente a um saber fazer correspondente. Em outras palavras, a produção de um saber fazer pressupõe a ação imediata em um domínio de ação específico; por isso, uma alteração de domínios, ou das circunstâncias, sempre coloca em questão o reconhecimento de uma expertise.

\section{Considerações Finais}

Nesse texto buscamos entender o modo como as formas de avaliação dos programas de pós-graduação no Brasil podem modular noções de habilidades acadêmicas baseadas, hoje, principalmente em publicações, invisibilizando outros processos que envolvem a produção de conhecimento e a experiência do pesquisador. Como consequência, pensamos a operatividade das políticas cognitivas na hierarquização de habilidades relacionadas ao pesquisar. Esse movimento desloca a noção de políticas cognitivas da ontologia da inventividade proposta por Kastrup (2006) para uma proposta de pesquisa que tem como foco as configurações da cognição em agenciamentos específicos. Em nosso caso, permitiu também uma conexão mais próxima com a teoria da enação e o conceito de habilidade, deliberando como modos específicos de valorização/desvalorização de habilidades produzem modos específicos da cognição existir.

A partir de nossas análises, ao entrelaçar produtivismo e habilidades cognitivas podemos perceber uma política cognitiva produtivista, que se organiza por meio do individualismo e dos resultados. $\mathrm{O}$ individualismo na cognição conecta-se implicitamente com a ideia de que aquilo que fazemos tem origem em uma representação interna e, portanto, o mérito individual deve ser recompensado, gerando simultaneamente competição entre os participantes (tanto por volume de publicação quanto por bolsas) e percepção de incapacidade entre aqueles que não conseguem alcançar os resultados esperados. Isto significa valorizar - no caso da engenharia - apenas habilidades lógico-matemáticas, obstruindo o desenvolvimento de habilidades ligadas à interação e compartilhamento de saberes entre pós-graduandos fundamentais para atividades diretamente ligadas com a pós-graduação e com a docência no ensino superior. Conforme referimos anteriormente, na teoria da enação, habilidades incorporadas se caracterizam pelo aumento gradual da sensibilidade de variáveis perceptuais relevantes e, concomitantemente, pelo ajuste e refinamento de ações relacionadas. A dinâmica do organismo estabelece uma reciprocidade com uma rede sociotécnica disponível, que inclui o conhecimento formalizado mas também relações de sociabilidade, elementos políticos e emocionais. Embora a leitura de instruções colabore para orientar a atenção a elementos visuais importantes assim como a algumas relações entre os elementos envolvidos - ainda é necessário o engajamento corporal para que a atividade seja desempenhada.

Essa discussão fica evidente, no caso de nossa pesquisa, quando discutimos aquilo que se institucionaliza como resultado de um estudo. Se nos voltamos para nosso caso da veterinária, percebemos que a experiência na pós-graduação delimita como habilidades válidas aquelas que podem ser exercidas dentro dos limites do estabelecimento de ensino: manipular instrumentos, redigir textos e interpretar tabelas, desconsiderando outras habilidades que sustentam a possibilidade de produção de artigos. Aqui, mais uma vez, habilidades relacionais (como lidar com o peão da fazenda) são desconsideradas assim como uma ampla gama de habilidades vinculadas ao trabalho no campo e ao engajamento com os animais, como verificar o sexo, coletar o pelo, marcar com ferro o número e observar a relação entre bezerros e a vaca. Discutido anteriormente, o obscurecimento dessas competências pode ser relacionado não apenas com a necessidade de produção de artigos, mas também com uma compreensão de ciência que percebe como resultado de ordem superior a conceituação abstrata (um saber-sobre), invisibilizando o trabalho manual (saber-fazer) que também o produz.

Cabe ressaltar, por fim, que nossa proposta de uma política cognitiva produtivista não se sobrepõe em todos os pontos às políticas cognitivas propostas 
por Kastrup (2006). Ao dividir sua análise entre políticas inventivas e recognitivas a autora oferece uma exploração metacognitiva, isso é, um balanço sobre como algumas práticas - em especial aquelas relacionadas às tecnologias digitais - produzem diferentes modos da cognição fazer referência a si mesma. Enquanto mantemos nossa atenção na rede de práticas que organiza o funcionamento da cognição, nossa análise se desloca para as habilidades desenvolvidas nessas práticas, ou seja, como somos capazes de efetivar certas ações aos estarmos inseridos em uma rede sociotécnica específica, ou ainda, que rede cognitiva de ações é constituída por um sujeito que se insere como ator nas atividades da pós-graduação.
Essa distinção fica ainda mais clara quando exploramos a ideia de resultado. Na política recognitiva, proposta por Kastrup, as práticas submetem o funcionamento cognitivo a seu resultado, sujeitando o processo ao produto e tornando o funcionamento cognitivo "uma espécie de lei transcendente” (Kastrup, 2006, p. 193) ${ }^{7}$. Uma política cognitiva produtivista estimula e valoriza um conjunto de habilidades diretamente conectado à elaboração de um produto ligado a um domínio cognitivo - de modo geral orientados pela avaliação institucional da CAPES -, como redigir um artigo ou programar um modelo. $\mathrm{O}$ uso e execução dessas habilidades pode ter dimensões inventivas e/ou recognitivas de acordo com práticas específicas que variam de local para local.

\section{Referências}

Andrade, J. S., Cassundé, F. R., \& Barbosa, M. A. C. (2019). Da liberdade à "gaiola de cristal": Sobre o produtivismo acadêmico na pós-graduação. Perspectivas Em Gestão \& Conhecimento, 9(1), 169-197. https://periodicos.ufpb.br/ ojs2/index.php/pgc/article/view/43356

Bachelard, G. (1971). Epistemologia. Lisboa: Edições 70.

Barros, L. M. R., \& Barros, M. E. B. (2013). O problema da análise em pesquisa cartográfica. Fractal: revista de Psicologia, 25(2), 373-390. https:// periodicos.uff.br/fractal/article/view/4948/4790

Brito, L. M. P. (2008). Gestão de competências, gestão do conhecimento e organizações de aprendizagem: Instrumentos de apropriação pelo capital do saber do trabalhador. Cadernos de Educação, (31), 203-225. https://periodicos.ufpel.edu.br/ojs2/index.php/caduc/article/view/1748/1628

Cabral, C. G. (2005). As mulheres nas escolas de engenharia brasileiras: História, educação e futuro. Cadernos de gênero e tecnologia, 1(4), 9-19. https:// periodicos.utfpr.edu.br/cgt/article/view/6139/3790

Castiel, L. D., \& Sanz-Valero, J. (2007). Entre fetichismo e sobrevivência: O artigo científico é uma mercadoria acadêmica? Cadernos de Saúde Pública, 23(12), 3041-3050. https:// doi.org/10.1590/S0102-311X2007001200026

Deluiz, N. (2001). O modelo das competências profissionais no mundo do trabalho e na educação: Implicações para o currículo. Boletim Técnico do Senac, 27(3), 12-25. https://www.bts.senac.br/bts/article/view/572

Estácio, L. S. S., Andrade, W. G. F., Kern, V. M., \& Cunha, C. J. C. A. (2019). O produtivismo acadêmico na vida dos discentes de pós-graduação. Em Questão, 25(1), 133-158. http://dx.doi.org/10.19132/1808-5245251.133-158

Gavillon, P., Baum, C., \& Maraschin, C. (2017). Dos modelos às políticas: O papel da representação nas ciências cognitivas. Estudos de Psicologia, 22(2), 144-151. http:// dx.doi.org/10.22491/1678-4669.20170015

Kastrup, V. (2001). Aprendizagem, arte e invenção. Psicologia Em Estudo, 6(1), 17-27. https://doi.org/10.1590/ s1413-73722001000100003

Kastrup, V. (2006). A invenção de si e do mundo: Uma introdução do tempo e do coletivo no estudo da cognição. São Paulo: Autêntica.

Latour, B. (2001). A esperança de Pandora. Bauru, SP: Edusc.

Lima, L. C. (2004). Do aprender a ser à aquisição de competências para competir: Adaptação, competitividade e performance na sociedade da aprendizagem. Revista Galego-Portuguesa de Psicoloxia e Educación, 11(9), 9-18. https://repositorium.sdum.uminho.pt/bitstream/1822/33998/1/Do\%20Aprender\%20a\%20ser....pdf

\footnotetext{
${ }^{7}$ As políticas inventivas, por sua vez, seriam aquelas que propiciam a problematização e que não esgotam seu exercício ao encontrar uma solução.
} 
Lourau, R. (2004). Analista institucional em tempo integral. São Paulo: Hucitec.

Maraschin, C., Baum, C., Teles, F, \& Roos, R. (2016). Tecnogeografias: Modulações nas ecologias e políticas cognitivas. Fractal: Revista de Psicologia, 28(2), 213-220. http://dx.doi.org/10.1590/1984-0292/1425

Maraschin, C., \& Sato, L. (2013). Recuperando leituras críticas sobre a avaliação na pós-graduação: Dando continuidadeà discussãoeaodebate. Psicologia\&Sociedade, 25(1),2-9.https://doi.org/10.1590/S0102-71822013000100002

McGann, M., De Jaegher, H., \& Di Paolo, E. (2013). Enaction and psychology. Review of General Psychology, 17(2), 203-209. https://doi.org/10.1037/a0032935

Olinto, G. (2011). A inclusão das mulheres nas carreiras de ciência e tecnologia no Brasil. Inclusão Social, 5(1), 68-77. http://revista.ibict.br/inclusao/article/view/1667

Rocha, M. L., \& Aguiar, K. F. (2010). Entreatos: Percursos e construções da psicologia na rede pública de ensino. Estudos e Pesquisas em Psicologia, 10(1), 68-84. https://doi.org/10.12957/epp.2010.9018

Rocha, T. G., \&Pinheiro, F.P.H.A. (2011). Políticas cognitivas da psicologia comunitária: Ameio caminho entre a recognição e a invenção. Psicologia \& Sociedade, 23(3), 486-495. https://doi.org/10.1590/S0102-71822011000300006

Sato, L., Teodoro, M. L. M., Linhares, M. B. M., Maraschin, C., \& Carneiro, H. F. (2012, junho). Inserção social: Relações entre a produção científica da pós-graduação em psicologia e a sociedade. Artigo apresentado no XIV Simpósio da ANPEPP, Belo Horizonte, MG. http://www.anpepp.org.br/old/4-Foruns/Pol-Cient/CPC-ForumTexto3-Insercao\%20Social.pdf

Tourinho, E. Z., \& Bastos, A. V. B. (2011, novembro). Desafios da pós-graduação em psicologia no Brasil. Palestra proferida na Sessão Especial apresentada na $41^{\text {a }}$ Reunião Anual da Sociedade Brasileira de Psicologia, Belém, PA. https://www.scielo.br/scielo.php?pid=S0102-79722010000400005 \&script=sci_arttext \&tlng=pt

Varela, F. J. (1996). Sobre a competência ética. Lisboa: Edições 70.

Varela, F. J., Thompson, E., \& Rosch, E. (2001). A mente corpórea: Ciência cognitiva e experiência humana. Lisboa: Instituto Piaget.

Vosgerau, D. S. R., Orlando, E. A., \& Meyer, P. (2017). Produtivismo acadêmico e suas repercussões no desenvolvimento profissional de professores universitários. Educação e Sociedade, 38(138), 231-247. https://doi.org/10.1590/ es0101-73302016163514

\section{Vanessa Maurente}

Professora do Departamento de Psicologia Social e Institucional da Universidade Federal do Rio Grande do Sul (UFRGS), Porto Alegre - RS. Brasil.

E-mail: vanessamaurente@yahoo.com.br

(1) https://orcid.org/0000-0003-1340-3450

\section{Carlos Baum - In memoriam}

Professor do Departamento de Psicologia Social e Institucional da Universidade Federal do Rio Grande do Sul (UFRGS), Porto Alegre - RS. Brasil.

\section{Renata Kroeff}

Mestre em Psicologia Social e Institucional e doutoranda em Psicologia Social e Institucional pela Universidade Federal do Rio Grande do Sul, Porto Alegre - RS. Brasil.

E-mail: kroeff.re@gmail.com

(1) https://orcid.org/0000-0002-9029-6647

Endereço para envio de correspondência:

Universidade Federal do Rio Grande do Sul. Rua Ramiro Barcelos, 2600, sala 401E, Santana. CEP: 90035-003.

Porto Alegre - RS. Brasil. 
Recebido 10/10/2018

Aceito 02/06/2020

Received 10/10/2018

Approved 06/02/2020

Recibido $10 / 10 / 2018$

Aceptado 02/06/2020

Como citar: Maurente, V. S., Baum, C., \& Kroeff, R. (2020). Política cognitiva produtivista: desenvolvimento e hierarquia de habilidades na pós-graduação. Psicologia: Ciência e Profissão, 40, 1-13. https://doi.org/10.1590/1982-3703003215231

How to cite: Maurente, V. S., Baum, C., \& Kroeff, R. (2020). Productive Cognitive Policy: Development and Hierarchy of Skills in Graduate Courses. Psicologia: Ciência e Profissão, 40, 1-13. https://doi.org/10.1590/1982-3703003215231

Cómo citar: Maurente, V. S., Baum, C., \& Kroeff, R. (2020). Política Cognitiva Productivista: Desarrollo y Jerarquía de Habilidades en el Posgrado. Psicologia: Ciência e Profissão, 40, 1-13. https://doi.org/10.1590/1982-3703003215231 